Short communication

\title{
Synthesis of $4^{\prime}$-(2-ferrocenyl)-2,2':6'2' $2^{\prime \prime}$-terpyridine: Characterization and antiprotozoal activity of $\mathrm{Mn}(\mathrm{II}), \mathrm{Co}(\mathrm{II}), \mathrm{Ni}(\mathrm{II}), \mathrm{Cu}(\mathrm{II})$ and $\mathrm{Zn}(\mathrm{II})$ complexes
}

\author{
Annu Juneja ${ }^{\mathrm{a}}$, Tais Soares Macedo ${ }^{\mathrm{b}}$, Diogo Rodrigo Magalhaes Moreira ${ }^{\mathrm{b}, \mathrm{c}}$, \\ Milena Botelho Pereira Soares ${ }^{\mathrm{b}, \mathrm{c}}$, Ana Cristina Lima Leite ${ }^{\mathrm{d}}$, \\ Juliana Kelle de Andrade Lemoine Neves ${ }^{e}$, Valeria Rego Alves Pereira ${ }^{\mathrm{e}}$, Fernando Avecilla ${ }^{\mathrm{f}}$, \\ Amir Azam ${ }^{\text {a,* }}$ \\ ${ }^{a}$ Department of Chemistry, Jamia Millia Islamia, Jamia Nagar, New Delhi 110025, India \\ b Centro de Pesquisas Gonçalo Moniz, Fundação Oswaldo Cruz, Rua Waldemar Falcão, 121, Candeal, 40296-710 Salvador, BA, Brazil \\ ${ }^{\mathrm{C}}$ Centro de Biotecnologia e Terapia Celular, Hospital São Rafael. Av. São Rafael, 2152, São Marcos, 41253-190 Salvador, BA, Brazil \\ ${ }^{\mathrm{d}}$ Department of Pharmaceutical Sciences, Centre for Health Sciences, Federal University of Pernambuco, 50740-520 Recife, PE, Brazil \\ ${ }^{\mathrm{e}}$ Departamento de Imunologia, Centro de Pesquisas Aggeu Magalhães, Fundação Oswaldo Cruz, 50670-420 Recife, PE, Brazil \\ f Departamento de Química Fundamental, Universidade da Coruña, Campus da Zapateira s/n, 15071 A Coruña, Spain
}

\section{A R T I C L E I N F O}

\section{Article history:}

Received 1 November 2013

Received in revised form

14 January 2014

Accepted 18 January 2014

Available online 31 January 2014

\section{Keywords:}

Metal complexes

Terpyridine

Ferrocenyl

Amoebiasis

Malaria

\begin{abstract}
A B S T R A C T
A terpyridine ligand Fctpy was reacted with divalent metals ( $\mathrm{Cu}, \mathrm{Co}, \mathrm{Mn}, \mathrm{Ni}$ and $\mathrm{Zn}$ ), yielding five complexes of general formula $\left[\mathrm{Metal}(\mathrm{Fctpy})_{2}\right]\left[\mathrm{PF}_{6}\right]_{2}$. The structure of Fctpy was determined by single crystal X-ray diffraction studies. The complexes characterized using various spectroscopic techniques suggested an octahedral geometry around the central metal ion. These complexes were screened for their antiamoebic, trypanocidal and antimalarial activities. It was found that, complexes $\mathbf{2}$ and $\mathbf{3}$ showed better $\mathrm{IC}_{50}$ values than metronidazole against HM1:IMSS strain of Entamoeba histolytica. A substantial parasitic inhibition was not observed for the trypanocidal activity. However, for the erythrocytic stage of W2 strain of Plasmodium falciparum, the complexes inhibited $\beta$-hematin formation. At the concentration of $10 \mu \mathrm{g} / \mathrm{mL}$, these complexes did not display toxicity.
\end{abstract}

(c) 2014 Elsevier Masson SAS. All rights reserved.

\section{Introduction}

Parasitic protozoa are known to cause a number of diseases, thereby affecting a large proportion of the world's population. The emergence and spread of multidrug-resistant Plasmodium falciparum, the most virulent human malaria parasite, is a major obstacle in controlling malaria [1] and so it remains one of the world's most prevalent tropical diseases. Most currently used drugs act against the parasite forms that invade erythrocytes and cause malarial symptoms [2]. Amoebiasis, caused by the enteric protozoan parasite Entamoeba histolytica, affects $10 \%$ of the world population [3,4]. It is an emerging parasitic complication in the human immunodeficiency virus (HIV)-infected patients $[5,6]$. The current treatment for this disease is mostly based on classical medicines, such as

\footnotetext{
* Corresponding author. Tel.: +91 11 26981717x3250; fax: +91 1126980229.

E-mail address: amir_sumbul@yahoo.co.in (A. Azam).
}

nitroimidazoles (metronidazole, tinidazole, and ornidazole). However, these drugs cause substantial side effects, such as gastrointestinal and neurological complications. The question of drug resistance is also a main concern [7,8]. American Trypanosomiasis or Chagas' disease is caused by the protozoan parasite Trypanosoma cruzi and is a major public health problem in Latin American countries [9] .The most common drugs used to treat the disease are nifurtimox and benznidazole, which present weakening side effects and low efficacy against the later chronic stage [10].

Terpyridines are versatile building blocks in bioinorganic chemistry [11,12]. From the chemical point of view, terpyridines function as meridional tridentate ligands, and the structural changes are restricted when the oxidation state of the centre changes. Based on this, one way to use terpyridines as ligands is combining them with other "auxiliary" ligands to prepare "mixed-

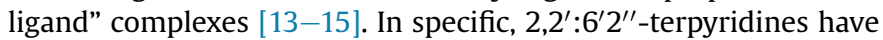
become a choice of metal-binding motif in metallosupramolecular 
chemistry [16,17]. Metals in complexation with terpyridines are largely known as DNA binders [18-20]. Because of this ability, terpyridine metal-complexes are described in many reports as antiproliferative agents, which make them attractive chemotherapeutic agents for cancer and infectious diseases [12,19,21]. Specifically, the example of terpyridine Pt(II) complexes should be cited that have been reported as potent antiprotozoal agents for Leishmania donovani, Trypanosoma cruzi, and Trypanosoma brucei $[18,22,23]$. Ferrocene is an important structural component of the anticancer drug ferrocifen and of the antimalarial drug ferroquine [24-28]. The coordination behaviour and molecular structure of ferrocene substituted terpyridine is already known [29]. In our laboratory, we have already reported a number of transition metal complexes which have shown very promising antiamoebic activity results when compared to the standard drug [30-34].

In the light of these evidences, the feasibility of preparing terpyridine complexes with other transition metals attracted our attention. Therefore, in this paper, we wish to present a terpyridine ligand denoted by Fctpy complexed with various metal ions. Fctpy is composed of $2,2^{\prime}: 6^{\prime} 2^{\prime \prime}$-terpyridine core, and coupled with a ferrocenyl group. To our knowledge, this is the first report describing the antiamoebic and antimalarial properties of ferrocenyl terpyridine transition metal complexes.

\section{Results and discussion}

\subsection{Synthesis and structural elucidation}

The synthesis of the ligand Fctpy was done using a reported method [35] and is depicted in Scheme 1 and gave a moderate yield. The reaction undergoes an aldol condensation reaction between 2-acetyl pyridine and the aldehyde, ferrocene-2carboxaldehyde, followed by a Michael addition of a second equivalent of 2-acetyl pyridine, yielding a 1,5-diketo derivative. This latter undergoes a ring closure upon reaction with ammonia to form the central pyridine ring. A sufficiently pure compound is further used as a ligand to complex with $\mathrm{MnCl}_{2} \cdot 6 \mathrm{H}_{2} \mathrm{O}, \mathrm{CoCl}_{2} \cdot 6 \mathrm{H}_{2} \mathrm{O}$, $\mathrm{NiCl}_{2} \cdot 6 \mathrm{H}_{2} \mathrm{O}, \mathrm{CuCl}_{2} \cdot 2 \mathrm{H}_{2} \mathrm{O}$ and $\mathrm{ZnCl}_{2}$, thereby generating the respective bis chelated complexes (1-5). Elemental analysis data (for $\mathrm{C}, \mathrm{H}$, and $\mathrm{N}$ ) confirmed the proposed metal-ligand ratio (1:2) and are in agreement with the calculated values. The IR spectral signatures of the ligand Fctpy showed characteristic bands at $2948 \mathrm{~cm}^{-1}, 1650 \mathrm{~cm}^{-1}$ and $1574 \mathrm{~cm}^{-1}$ assigned respectively to $(v \mathrm{Ar}-\mathrm{H}),(v \mathrm{C}=\mathrm{N})$ and $(v \mathrm{C}=\mathrm{C})$ stretching. For the metal complexes, although no appreciable shifts in the vibrations attributed to ( $v \mathrm{Ar}-$ $\mathrm{H})$ and $(v \mathrm{C}=\mathrm{C})$ of the pyridine ring were observed, absorption due to $(v \mathrm{C}=\mathrm{N})$ at $1650 \mathrm{~cm}^{-1}$ was seen shifting to lower frequency, rough to $30-50 \mathrm{~cm}^{-1}$ after the metallic complexation. This indicates the participation of pyridine ring nitrogen in the coordination. Moreover, the bands in the low-wave number region of $470-504 \mathrm{~cm}^{-1}$ were assigned to $(v \mathrm{M}-\mathrm{N})$. The ${ }^{1} \mathrm{H}$ NMR spectra of the ligand as well as the complexes were recorded in $\mathrm{CD}_{3} \mathrm{CN}$ and found to be consistent with the number of protons and hence the proposed compositions. In case of metal complexes, there was no appreciable change in the chemical shifts of the protons and the two types of protons, i.e. the ferrocene protons and the aromatic protons were seen resonating in their expected regions after the complexation with only a slight difference in their multiplicities as given in the experimental section. The structural characteristics of these complexes were further delivered by a careful examination of
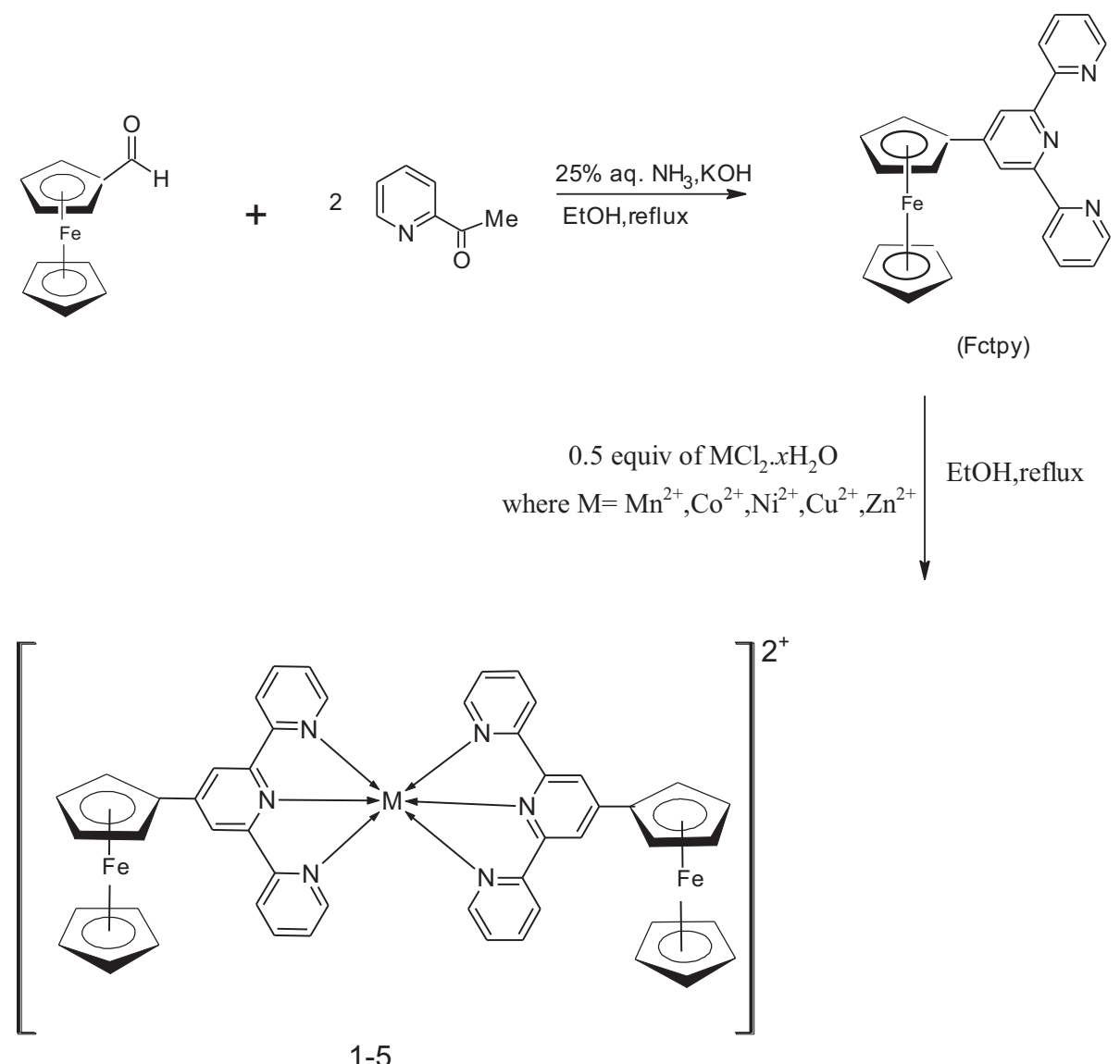

Scheme 1. Synthesis of ligand Fctpy and its metallic complexes (1-5). 
their thermogravimetric patterns. Table S1 provides weight loss of complexes at various steps. All the metal complexes contain some residual water as they lose ca. $1-4$ percent weight below $120^{\circ} \mathrm{C}$. Thereafter complexes are stable but decompose in three major steps. All the five complexes lose $12-37 \%$ weight between 200 and $350{ }^{\circ} \mathrm{C}, 12-46 \%$ in the range $350-500{ }^{\circ} \mathrm{C}$ and $2-11 \%$ in the range $500-750{ }^{\circ} \mathrm{C}$. All the decomposing steps are endothermic and overlapping, and it was not possible to estimate the loss of a particular group due to complicated structure of the complex. Similarly, the obtained residues were very difficult to identify as the complexes contain Fe and P along with the central metal ion, viz., $\mathrm{Mn}(\mathrm{II}), \mathrm{Co}(\mathrm{II}), \mathrm{Ni}(\mathrm{II}), \mathrm{Cu}(\mathrm{II})$ and $\mathrm{Zn}$ (II) and it is likely that the residue contains a mixture of phosphates of the central metal ion and $\mathrm{Fe}$ (see Supporting information).

Several attempts made to obtain single crystals of metal complexes suitable for X-ray diffraction were unsuccessful; therefore, additional analyses were done and studied well. The mass spectra of the ligand and its metal complexes have showed the expected fragment ions, confirming the respective molecular weights. In the electronic spectrum of manganese complex, absorption bands at 312-303, 292-262 and 252-207 $\mathrm{nm}$ may be assigned to $\mathrm{n} \rightarrow \pi^{*}$, $\pi \rightarrow \pi^{*}$ and $\mathrm{n} \rightarrow \sigma^{*}$ high energy transitions, respectively, while the same transitions were observed at 315-302, 278-258 and 234$201 \mathrm{~nm}$ for the cobalt complex. Similarly, for the copper complex, not much of a difference was observed for the above three high energy transitions and they appeared at 327-301, 267-252 and 231-202 nm, respectively. The transitions due to the pyridyl groups $(\mathbf{C}=\mathbf{N})$ present in the manganese, cobalt and copper ferrocenyl terpyridine complexes presented their bands at 312-303, 315-302 and 327-301 nm, respectively. Moreover, manganese complex displayed four $\mathrm{d}-\mathrm{d}$ transitions at 583-564, 432-420, 356-345 and $310-288 \mathrm{~nm}$ which might be assigned to ${ }^{6} \mathrm{~A}_{1} \mathrm{~g} \rightarrow{ }^{4} \mathrm{~T}_{1} \mathrm{~g}(4 \mathrm{G})$, ${ }^{6} \mathrm{~A}_{1} \mathrm{~g} \rightarrow{ }^{4} \mathrm{Eg}$ and ${ }^{4} \mathrm{~A}_{1} \mathrm{~g}(4 \mathrm{G}),{ }^{6} \mathrm{~A}_{1} \mathrm{~g} \rightarrow{ }^{4} \mathrm{Eg}(4 \mathrm{D})$ and ${ }^{6} \mathrm{~A}_{1} \mathrm{~g} \rightarrow{ }^{4} \mathrm{~T}_{1} \mathrm{~g}(4 \mathrm{P})$ respectively which support the fact that the manganese ion assumes octahedral geometry in the complex. Cobalt complex displayed two d-d transitions at 537 and $462 \mathrm{~nm}$ assigned to $4 \mathrm{~A}_{2} \mathrm{~g}(\mathrm{~F}) \leftarrow 4 \mathrm{~T}_{1} \mathrm{~g}(\mathrm{~F})$ and $4 \mathrm{~T}_{1} \mathrm{~g}(\mathrm{P}) \leftarrow 4 \mathrm{~T}_{1} \mathrm{~g}(\mathrm{~F})$ respectively, which are in accordance with tetragonally distorted octahedral geometry around the $\mathrm{Co}^{2+}$ ion. The copper complex displayed two ligand field bands in the region 444-544 and 384-401 nm assigned to ${ }^{2} \mathrm{~T}_{2 \mathrm{~g}} \leftarrow{ }^{2} \mathrm{E}_{\mathrm{g}}$ transition and charge transfer bands, respectively, which are in accordance with a tetragonally distorted octahedral [36] geometry around the $\mathrm{Cu}^{2+}$ ion.

Steady-state fluorescence analysis of the five complexes shows very weak fluorescence centred in the vicinity of $420 \mathrm{~nm}$ when excited at $370 \mathrm{~nm}$ (Fig. 1). The absence of appreciable fluorescence is attributed to the presence of metal which usually enhances singlet to triplet intersystem crossing, thus increasing the overall non-radiative decay rates [37]. Even weaker broad fluorescence features for the metal complexes are seen around $700 \mathrm{~nm}$ when excited at $520 \mathrm{~nm}$ (data not shown). The fluorescence characteristics are in agreement with what are reported earlier for similar compounds [38,39] (see Supporting information).

The EPR spectra of the complexes 3 and 4 were measured in DMF solution at $77 \mathrm{~K}$. In axial symmetry, the $g$ values are related by the expression, $G=\left(g_{\|}-2.0023\right) /\left(g_{\perp}-2.0023\right)$, where $G$ is the exchange interaction parameter. According to Hathaway [40], the exchange interaction between copper (II) centres in the solid state is negligible if $G>4$, but a considerable exchange interaction is indicated in the solid complex if $G<4$. The ESR spectrum of [Ni(Fctpy) $\left.)_{2}\right]\left[\mathbf{P F}_{\mathbf{6}}\right]_{\mathbf{2}}$ exhibits an axially symmetric g-tensor parameters with $g_{\|}, 2.177>g_{\perp}, 2.125>2.0023$. Superhyperfine structure for the complex is not observed at a high field excluding any interaction of the nuclear spin of the nitrogen $(I=1)$ with the unpaired electron density on $\mathrm{Ni}(\mathrm{II})$ ion. An increase or decrease in

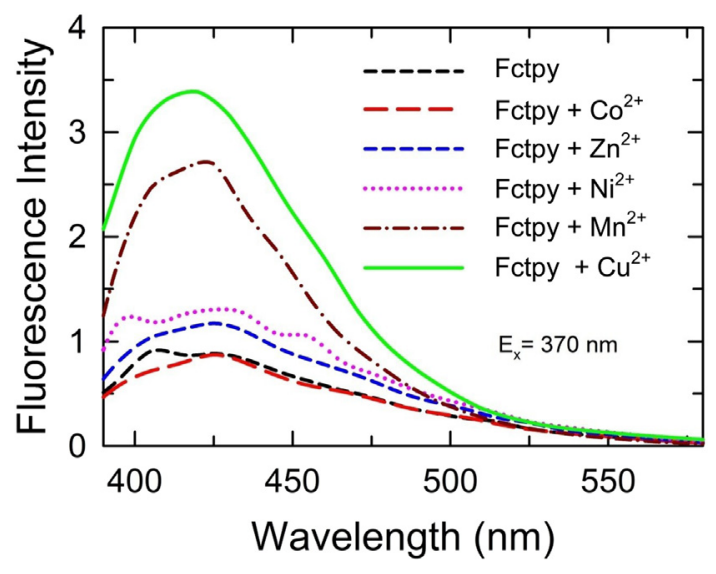

Fig. 1. Fluorescence emission spectra of Fctpy alone and Fctpy in the presence of various metal cations in acetonitrile at ambient conditions ([Fctpy] $=25 \mu \mathrm{M}$, excitation wavelength $=370 \mathrm{~nm}$, slit widths $=10$ and $10 \mathrm{~nm}$ ) (see Supporting information).

the $g$ values than the value of the free electron, 2.0033, will lead to increase or decrease the positive or negative contribution respectively to the covalent character between the ligand under investigation and the $\mathrm{Ni}(\mathrm{II})$ ion.

The $g_{\text {eff }}$ for $\left[\mathbf{C u}(\mathbf{F c t p y})_{2}\right]\left[\mathbf{P F}_{\mathbf{6}}\right]_{\mathbf{2}}$ complex shows generally one strong broad signal with no hyperfine splitting, on amplification and expansion broad signal is observed. The pattern and shape of the signal together with the $g$ value of the complex may indicate octahedral geometry around $\mathrm{Cu}(\mathrm{II})$ ion (see Supporting information)

\subsubsection{Single crystal structure of $\left[\mathrm{CpFe}\left(\eta^{5}-\mathrm{C}_{5} \mathrm{H}_{4}-\mathrm{tpy}\right)\right]$, Fctpy}

$\left[\mathrm{CpFe}\left(\eta^{5}-\mathrm{C}_{5} \mathrm{H}_{4}\right.\right.$-tpy $\left.)\right]$, Fctpy, crystallizes from acetonitrileethanol solution as dark orange prism (crystal dimensions $0.135 \times 0.180 \times 0.220 \mathrm{~mm}$ ). Fig. 2 shows an ORTEP representation of $\left[\mathrm{CpFe}\left(\eta^{5}-\mathrm{C}_{5} \mathrm{H}_{4}\right.\right.$-tpy $\left.)\right]$. The $\mathrm{Cp}$ rings $\left[\mathrm{Cp}^{1}\right.$ containing $\mathrm{C}(1)-\mathrm{C}(5)$, and $\mathrm{Cp}^{2}$ containing $\left.\mathrm{C}(6)-\mathrm{C}(10)\right]$ of the ferrocenyl group are

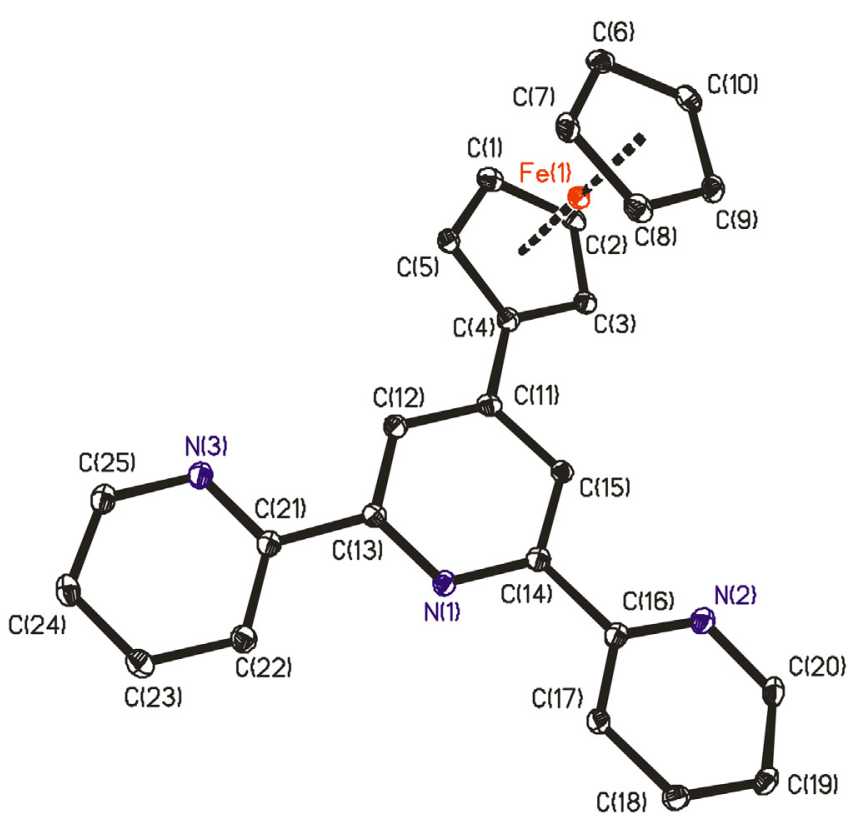

Fig. 2. ORTEP plot for the complex of [ $\mathrm{CpFe}\left(\eta^{5}-\mathrm{C}_{5} \mathrm{H}_{4}\right.$-tpy $\left.)\right]$, Fctpy. All the non-hygrogen atoms are presented by their $30 \%$ probability ellipsoids. Hydrogen atoms are omitted for clarity. 
approximately eclipsed $\left(4.9^{\circ}\right.$ twist about the edge joining the ring centroids) with an interplanar angle of $1.9^{\circ}$ (Fig. 4). The variations in the $\mathrm{Fe}-\mathrm{C}$ bond lengths are small, 2.039(3)-2.054(2) (mean $2.0435 \AA$ ), similar to other compounds with substituents bonded to the $\mathrm{Cp}$ rings [41]. The longer distance involving to the carbon bearing the substituent tpy group $[\mathrm{Fe}(1)-\mathrm{C}(4) 2.054(2) \AA]$. The distance between $\mathrm{Fe}$ and the centroid of the $\pi$-bonded cyclopentadienyl moiety are $1.650(3) \AA$ to $\mathrm{Cp}^{1}$ (ring slippage $0.012 \AA$ ), and 1.649 (3) $\AA$ to $\mathrm{Cp} 2$ (ring slippage $0.007 \AA$ ), in Fctpy. The tpy unit is not co-planar with the parent $\mathrm{Cp}$ rings as indicate the interplanar angle between the $\mathrm{Cp}$ moieties and central ring of the tpy group [19.60 (14) ${ }^{\circ} \mathrm{Cp}^{1}-\mathrm{N}(1)$ ring, and $20.34(14)^{\circ} \mathrm{Cp}^{2}-\mathrm{N}(1)$ ring]. The two external py rings are inclined at an angle of $14.03(13)^{\circ}$ with respect to each other. $\pi-\pi$ stacking could account between the external py groups of the tpy substituents of an inversion-related molecule (mean separation between the py rings ca $3.74 \AA$ ) in the crystal packing (Fig. 3). Table S2 contains selected bond lengths and angles for compound Fctpy.

\subsection{Pharmacological screening}

The metal complexes were tested for HM1:IMSS strain of E. histolytica, Y strain Trypanosoma cruzi epimastigotes, and for the erythrocytic stage of W2 strain $P$. falciparum. The antiparasitic activity ( $\mathrm{IC}_{50}$ values) and the toxicity of compounds for mouse splenocytes are summarized in Table 1. Metronidazole (MNZ) was used as a reference amoebicidal drug, while benznidazole $(\mathrm{Bdz})$ and mefloquine (MQN) were used as reference drugs for T. cruzi and $P$. falciparum respectively.

The ligand Fctpy has low potency to inhibit the proliferation of E. histolytica $\left(\mathrm{IC}_{50}\right.$ of $37.9 \pm 0.02 \mu \mathrm{M}$ ). In this same experiment, metronidazole, which is currently used for amoebiasis treatment, displayed an $\mathrm{IC}_{50}$ value of $1.46 \pm 0.002 \mu \mathrm{M}$. The $\mathrm{IC}_{50}$ value found for metronidazole is consistent with our previous works, where its generally observed $\mathrm{IC}_{50}$ value has been found to be below $2.0 \mu \mathrm{M}$ $[32,34]$. Having ascertained the $\mathrm{IC}_{50}$ values for Fctpy and metronidazole, the metal complexes were tested further. The amoebicidal activity results for the metal complexes prepared from Fctpy were found to be very promising. Complexes 2 and 3, i.e., [Co(Fctpy $)_{2}$ ] $\left[\mathrm{PF}_{6}\right]_{2}$ and $\left[\mathrm{Ni}(\mathrm{Fctpy})_{2}\right]\left[\mathrm{PF}_{6}\right]_{2}$ have $\mathrm{IC}_{50}$ values of $0.12 \pm 0.02$ and $0.06 \pm 0.02 \mu \mathrm{M}$ for E. histolytica trophozoites. Except for $\left[\mathrm{Mn}(\mathrm{Fctpy})_{2}\right]\left[\mathrm{PF}_{6}\right]_{2}$, which is slightly less potent, all the other metal

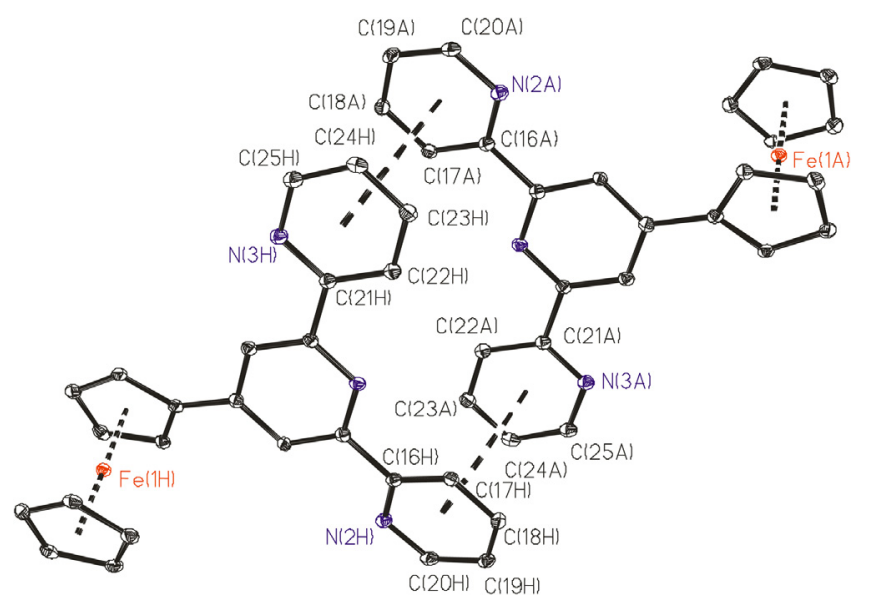

Fig. 3. Crystal packing of $\left[\mathrm{CpFe}\left(\eta^{5}-\mathrm{C}_{5} \mathrm{H}_{4}\right.\right.$-tpy $\left.)\right]$, Fctpy. All the non-hygrogen atoms are presented by their $30 \%$ probability ellipsoids. Hydrogen atoms are omitted for clarity. $\pi-\pi$ stacking between py groups are presented in dashed lines (see Supporting information).

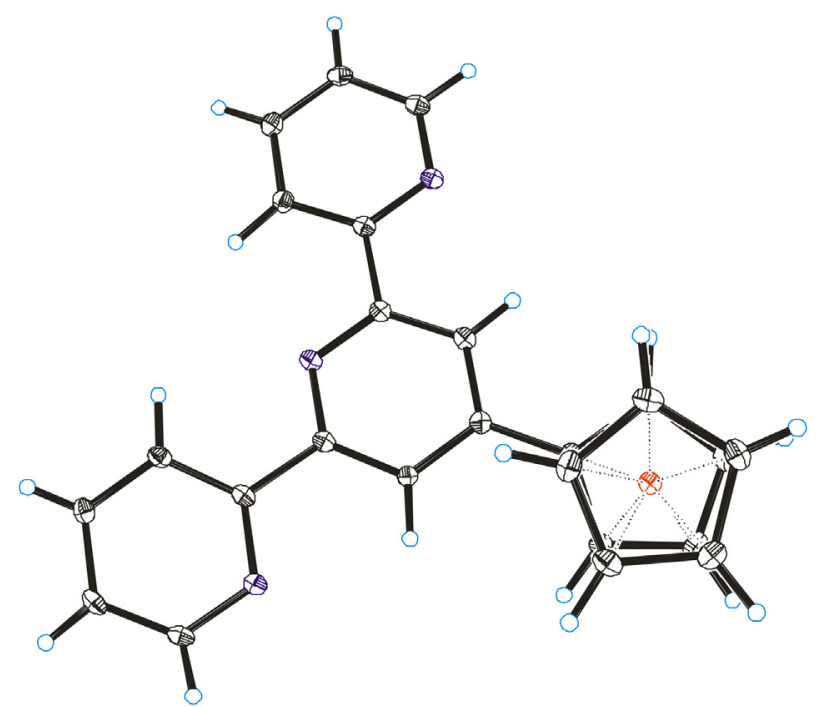

Fig. 4. Ortep plot of [ $\mathrm{CpFe}\left(\eta^{5}-\mathrm{C}_{5} \mathrm{H}_{4}\right.$-tpy $\left.)\right]$, Fctpy, highlighting the eclipsed geometry. All the non-hygrogen atoms are presented by their $30 \%$ probability ellipsoids.

complexes were at least five times more potent amoebicidal agents than metronidazole.

To make sure that these complexes are selective amoebicidal agents, evaluation of their toxicity for host cells (i.e., mammalian cells) was done. At the concentration of up to $8 \mu \mathrm{M}$, these complexes did not affect the viability of mouse splenocytes (Table 1). This observation favours these compounds acting on parasites rather than mammalian cells.

Once the amoebicidal activity was determined, these complexes were assayed for epimastigotes of Y strain Trypanosoma cruzi and for the erythrocytic stage of W2 strain P. falciparum. As seen in Table 1, substantial anti-T. cruzi activity could not be identified when compared to the reference drug, benznidazole.

Manganese, cobalt and zinc complexes (1, 2 and 5, respectively) with $\mathrm{IC}_{50}$ values of $1.1 \pm 1.1,1.9 \pm 0.9$, and $1.5 \pm 0.1 \mu \mathrm{M}$ respectively, exhibited their potency as inhibitors of $P$. falciparum, while the ligand (Fctpy) displayed an $\mathrm{IC}_{50}$ value of $3.0 \pm 1.9 \mu \mathrm{M}$. Therefore, the most potent metal complexes are at least ten times more potent than the ligand (Fctpy). After exploring the antimalarial properties of metal complexes, the tendency of the compounds to inhibit the haemin polymerization was determined (Table 2 ). This was assayed using a previously mentioned method. The ligand (Fctpy) inhibited the haemin polymerization, but this inhibitory property is enhanced for the metal complexes. All the metal complexes showed potency comparable to Chloroquine, the standard haemin polymerization inhibitor. It would, therefore, seem to be fair to suggest that the antimalarial activity observed for metal complexes is, somehow, because of the metal complexes affecting the haemin polymerization in parasite cells.

The fact the ligand Fctpy has antiparasitic activities, although of low potency, confirms that our structural design was successfully accomplished. Moreover, the observation that the complexes $(\mathbf{1}-\mathbf{5})$ were more potent than the ligand Fctpy suggests the presence of a coordinated metal around Fctpy is essential for potency enhancement. From the literature, it is known that metal complexes dissociate in the cellular media and release the transition metal [42]. Once the cationic metal is released, it interacts with the parasite cells, culminating in toxic events for the parasite [43]. This also makes sense with our previous work, where it has been observed that metal complexes are substantially more potent amoebicidal and antimalarial agents than the ligands $[44,45]$. 
Table 1

Antiparasitic activities.

\begin{tabular}{|c|c|c|c|c|}
\hline Compound & $\begin{array}{l}\text { E. histolytica } \mathrm{HM} 1 \text { strain } \\
\mathrm{IC}_{50} \mu \mathrm{M} \text { after } 72 \mathrm{~h}^{\mathrm{a}}\end{array}$ & T. cruzi epimastigotes $\mathrm{IC}_{50}$ in $\mu \mathrm{M}^{\mathrm{b}}$ & P. falciparum \% inhibition at $10 \mu \mathrm{M}^{\mathrm{c}}$ & Mouse splenocytes $(\mu \mathrm{M})^{\mathrm{d}}$ \\
\hline Fctpy & $37.9( \pm 0.02)$ & NT & 85.1 & NT \\
\hline (1) $\left[\mathrm{Mn}(\text { Fctpy })_{2}\right]\left[\mathrm{PF}_{6}\right]_{2}$ & $5.03( \pm 0.01)$ & ND & 53.2 & $>8.5$ \\
\hline (2) $\left[\mathrm{Co}(\text { Fctpy })_{2}\right]\left[\mathrm{PF}_{6}\right]_{2}$ & $0.12( \pm 0.02)$ & 89.1 & 24.6 & 8.4 \\
\hline (3) $\left[\mathrm{Ni}(\text { Fctpy })_{2}\right]\left[\mathrm{PF}_{6}\right]_{2}$ & $0.06( \pm 0.02)$ & 60.8 & 21.2 & $>8.5$ \\
\hline (4) $\left[\mathrm{Cu}(\text { Fctpy })_{2}\right]\left[\mathrm{PF}_{6}\right]_{2}$ & $0.2( \pm 0.01)$ & 92.8 & 65.3 & 8.4 \\
\hline (5) $\left[\mathrm{Zn}(\text { Fctpy })_{2}\right]\left[\mathrm{PF}_{6}\right]_{2}$ & $0.1( \pm 0.01)$ & 50.4 & 52.5 & $>8.5$ \\
\hline MNZ & $1.46( \pm 0.002)$ & - & - & - \\
\hline BDZ & - & 1.73 & - & 89.2 \\
\hline
\end{tabular}

a Determined after $72 \mathrm{~h}$ of incubation of $E$. histolytica trophozoites with the compounds. IC $\mathrm{C}_{50}$ was calculated from five concentrations using data obtained from at least three independent experiments (SD given in parenthesis).

${ }^{b}$ Determined after 11 days of incubation of Y strain epimastigotes with the compounds. $\mathrm{IC}_{50}$ was calculated from five concentrations using data obtained from at least two independent experiments (SD less than 10\%).

${ }^{c}$ Determined by the $\left[{ }^{3} \mathrm{H}\right]$-hypoxanthine uptake method after $24 \mathrm{~h}$ of incubation of W2 strain parasite in the presence of the test-inhibitors.

d Toxicity for BALB/c splenocytes after $24 \mathrm{~h}$ of incubation in the presence of the compounds. Values mean the concentration that did not affect cell viability for more than $10 \%$

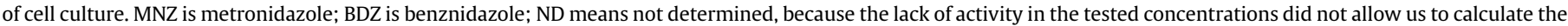
$\mathrm{IC}_{50}$ values. NT is not tested.

\subsection{SAR study}

The analysis of the pharmacological results showed that the ligand Fctpy is a very weak E. histolytica inhibitor. However, it is moderately active against $P$. falciparum, but is still many times less potent than MQN. Since there is only one ligand, and all its complexes adopted same geometry, therefore, SAR results could not be obtained from this data. So the most appropriate discussion of the biological results can be made only through the comparison between the metal complexes and the ligand for various assays. The antiamoebic activity of all except one complex showed improved potency against $E$. histolytica when compared to the ligand. On the other hand, in case of T. cruzi, both the ligand and the complexes did not show any activity when compared to BDZ. Further, the inhibition against $P$. falciparum was exhibited by complexes 1,2 and 5 and the potency was much better than the ligand Fctpy. The tendency of the complexes to inhibit the haemin polymerization presented promising results and all the complexes showed inhibition comparable to chloroquine. This provides evidence for these complexes to exhibit antimalarial activity. The increase in biological activity of the metal chelates may be due to the effect of the metal ion on the normal cell process. A possible mode of toxicity increase may be considered in the light of Tweedy's chelation theory [46]. Chelation considerably reduces the polarity of the metal ion because of partial sharing of its positive charge with the donor group and possible $\pi$ electron delocalization within the whole chelate ring system that is formed during coordination. Such chelation could enhance the lipophilic character of the central metal atom and hence increase the hydrophobic character and liposolubility of the complex favouring its permeation through the lipid layers of the cell membrane. This enhancement in activity may be attributed to the structural changes taking place in vitro during the assaying and it is suggested that the metal-ligand interactions are a major deciding factor responsible for the increase in anti-protozoal activity.

\section{Conclusion}

Using a new synthesized terpyridine ligand, denoted here as Fctpy, was used to prepare a series of metal complexes. It can be concluded that the complexes of general formula [Metal(Fctpy) 2 ] $\left[\mathrm{PF}_{6}\right]_{2}$ are endowed with amoebicidal and antimalarial properties but not with anti-T. cruzi activities. These complexes do not affect the cell viability (toxicity) of mouse splenocytes in concentrations of up to $8 \mu \mathrm{M}$. In other words, they acted as antiparasitic agents at concentrations that do not overtly affect mammalian cells. In special, these complexes are the most potent amoebicidal agents so far identified in our group, being equipotent to metronidazole. Molecular modifications in the ligand Fctpy as well as using other transition metals are the future goals.

\section{Experimental section}

\subsection{General remarks}

All the chemicals were purchased from Aldrich Chemical Company (USA). Precoated aluminium sheets (silica gel 60 F254, Merck Germany) were used for thin-layer chromatography (TLC) and spots were visualized under UV light. Elemental analysis $(\mathrm{C}, \mathrm{H}$, and N) and Electrospray (ES) mass spectra were carried out by Central Drug Research Institute, Lucknow, India. Melting points were recorded on a KSW melting point apparatus and were uncorrected. UV-visible electronic absorption spectra were recorded on a Perkin Elmer Lambda 35 spectrophotometer in the wavelength range of 200-800 nm using a $1 \mathrm{~cm}$ quartz cuvette at ambient conditions. Fluorescence spectra were acquired on model FL 3-11, Fluorolog-3 modular spectrofluorometer with single Czerny-Turner grating excitation and emission monochromators having $450 \mathrm{~W}$ Xe arc lamp as the excitation source and PMT as the detector purchased from Horiba-Jobin Yvon, Inc. IR spectra were recorded as $\mathrm{KBr}$ discs on a Perkin Elmer model 1620 FT-IR spectrophotometer. ${ }^{1} \mathrm{H}$ NMR spectra were obtained at ambient temperature using a Bruker spectrospin DPX-300 MHz instrument in $\mathrm{CD}_{3} \mathrm{CN}$ and using tetramethylsilane as an internal standard. Chemical shift values are given in ppm. Electron paramagnetic resonance (EPR) spectra in frozen DMF solution were obtained in quartz tubes of $3 \mathrm{~mm}$ of internal diameter at $77 \mathrm{~K}$ on Bruker ESP300E equipment. Spectral analyses were simulated on EasySpin software and tetracyanoethylene was used as standard signal. Thermograms of the complexes were recorded under nitrogen on a TG 51 thermogravimetric analyzer with increasing the temperature at $10{ }^{\circ} \mathrm{C} \mathrm{min}-1$. X-Ray crystal structure determination of Fctpy was done using a Bruker SMART Apex CCD diffractometer at $100(2) \mathrm{K}$, using a graphite monochromator and Mo- $K_{\alpha}$ radiation $(\lambda=0.71073 \AA)$ by the $\phi-\omega$ scan method. Reflections were measured from a hemisphere of data collected of frames each covering $0.3^{\circ}$ in $\omega$. Of the 38,934 reflections measured in Fctpy, all of which were corrected for Lorentz and polarization effects, and for absorption by semi-empirical methods based on symmetry-equivalent and repeated reflections, 2788 independent reflections exceeded the significance level $|F| / \sigma(F)>4$.0. Complex scattering factors were taken from the 
Table 2

Antimalarial and inhibition of haemin polymerization.

\begin{tabular}{llll}
\hline Compound & $\begin{array}{l}\text { P. falciparum } \\
\left(\mathrm{IC}_{50}, \mu \mathrm{M}\right)^{\mathrm{a}}\end{array}$ & $\begin{array}{l}\text { \% Inhibition of } \\
\text { haemin at } 2.0 \mathrm{mM}\end{array}$ & $\begin{array}{l}\text { Inhibition of } \\
\text { haemin }\left(\mathrm{IC}_{50}, \mathrm{mM}\right)^{\mathrm{b}}\end{array}$ \\
\hline Fctpy & $3.0 \pm 1.9$ & $46.5 \pm 3.6$ & $>2.0$ \\
$(\mathbf{1})\left[\mathrm{Mn}(\mathrm{Fctpy})_{2}\right]\left[\mathrm{PF}_{6}\right]_{2}$ & $1.1 \pm 1.1$ & $91.8 \pm 1.8$ & $0.41 \pm 0.04$ \\
$(\mathbf{2})\left[\mathrm{Co}(\mathrm{Fctpy})_{2}\right]\left[\mathrm{PF}_{6}\right]_{2}$ & $1.9 \pm 0.9$ & $91.5 \pm 3.5$ & $0.76 \pm 0.1$ \\
$(\mathbf{3})\left[\mathrm{Ni}(\mathrm{Fctpy})_{2}\right]\left[\mathrm{PF}_{6}\right]_{2}$ & $2.7 \pm 1.2$ & $89.4 \pm 3.4$ & $0.95 \pm 0.1$ \\
$(\mathbf{4})\left[\mathrm{Cu}(\mathrm{Fctpy})_{2}\right]\left[\mathrm{PF}_{6}\right]_{2}$ & $6.52 \pm 2.4$ & $88.7 \pm 0.9$ & $0.63 \pm 0.2$ \\
$(\mathbf{5})\left[\mathrm{Zn}(\text { Fctpy })_{2}\right]\left[\mathrm{PF}_{6}\right]_{2}$ & $1.5 \pm 0.14$ & $51.9 \pm 7.3$ & $0.61 \pm 0.1$ \\
Chloroquine & - & $83.1 \pm 2.7$ & $0.84 \pm 0.3$ \\
MQN & $0.04 \pm 0.01$ & - & - \\
\hline
\end{tabular}

a Determined by the $\left[{ }^{3} \mathrm{H}\right]$-hypoxanthine uptake after $24 \mathrm{~h}$ of incubation of W2 strain parasite in the presence of the test-inhibitors. Two independent experiments performed in triplicate concentrations. Standard deviation less than $10 \%$.

b Determined after $24 \mathrm{~h}$ of incubation of metal complexes. MQN is mefloquine.

program package SHELXTL [47]. The structures were solved by direct methods and refined by full-matrix least-squares methods on $\mathrm{F}^{2}$. The non-hydrogen atoms were refined with anisotropic thermal parameters in all cases. The hydrogen atoms were left to refine freely. A final difference Fourier map showed no residual

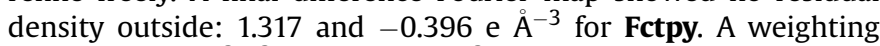
scheme $w=1 /\left[\sigma^{2}\left(F_{0}^{2}\right)+(0.061900 P)^{2}+1.253300 P\right]$ for Fctpy, where $P=\left(\left|F_{\mathrm{O}}\right|^{2}+2\left|F_{\mathrm{C}}\right|^{2}\right) / 3$, were used in the latter stages of refinement. CCDC 908385 contains the supplementary crystallographic data for the structure reported in this paper. These data can be obtained free of charge via http://www.ccdc.cam.ac.uk/conts/retrieving.html, or from the Cambridge Crystallographic Data Centre, 12 Union Road, Cambridge CB2 1EZ, UK; fax: (+44) 1223336 033; or e-mail: deposit@ccdc.cam.ac.uk. Crystal data and details of the data collection and refinement for the new compounds are collected in Table S3.

\subsubsection{Synthesis of terpyridine derivatives: 4'-(2-ferrocenyl)-2, $2^{\prime}: 6^{\prime} 2^{\prime \prime}$-terpyridine (Fctpy)}

To a solution of 2-acetyl pyridine ( $5.66 \mathrm{~g}, 46.72 \mathrm{mmol}, 2$ equiv.) in ethanol $(100 \mathrm{~mL})$, were added ferrocene-2-carboxaldehyde (5.0 g, $23.36 \mathrm{mmol}, 1$ equiv.), potassium hydroxide (3.60 g, $64.24 \mathrm{mmol}, 2.75$ equiv.) and ammonia solution $(100 \mathrm{~mL})$. The resulting mixture was heated at reflux and monitored using TLC. The resulting chocolate brown precipitate was filtered off and successively washed with water $(4 \times 25 \mathrm{~mL})$ and cold $50 \%$ ethanol $(25 \mathrm{~mL})$. The final product was first air dried and then in a dessicator over calcium chloride (4.66 g, $47.8 \%$ ). M.p. $310{ }^{\circ} \mathrm{C}$ (decomp); Elemental analysis calcd (\%) for $\mathrm{C}_{25} \mathrm{H}_{19} \mathrm{~N}_{3} \mathrm{Fe}$ : C 71.94, $\mathrm{H} 4.55, \mathrm{~N}$ 10.07; found: C 71.71, H 4.57, N 9.88; ES-MS: $m / z$ : $418[\mathrm{M}]^{+}$; FTIR $(\mathrm{KBr}): v_{\max / \mathrm{cm}}^{-1} 2948(\mathrm{C}-\mathrm{H}), 1650(\mathrm{C}=\mathrm{N}), 1574(\mathrm{C}=\mathrm{C}) ;{ }^{1} \mathrm{H}$ NMR (300 MHz, $\left.\mathrm{CD}_{3} \mathrm{CN}\right) \delta(\mathrm{ppm}): 8.758-8.661$ (m, 5H, py), 8.524 (bs, $2 \mathrm{H}$, py), 7.988-7.875 (m, 3H, py), 5.016-4.914 (m, 2H, fc), 4.620-4.468 (m, 2H, fc), 4.099 (s, 5H, fc).

\subsubsection{General procedure for the preparation of the complexes of $4^{\prime}-$}

(2-ferrocenyl)-2,2':6' $2^{\prime \prime}$-terpyridine (Fctpy), $\left[M(f c t p y)_{2}\right]\left[\mathrm{PF}_{6}\right]_{2}$

To a hot solution of Fctpy ( $2 \mathrm{mmol})$ in ethanol $(20 \mathrm{ml})$ was added a solution of the metal chloride, $\mathrm{MCl}_{2} \cdot x \mathrm{H}_{2} \mathrm{O}(1 \mathrm{mmol}),[\mathrm{M}=\mathrm{Mn}(\mathrm{II})$, $\mathrm{Co}(\mathrm{II}), \mathrm{Ni}(\mathrm{II}), \mathrm{Cu}(\mathrm{II})$ and $\mathrm{Zn}(\mathrm{II})]$, dissolved in minimum quantity of ethanol and the reaction mixture was heated under reflux for $2-$ $4 \mathrm{~h}$. After cooling the solution to room temperature, an excess of aqueous $\mathrm{NH}_{4} \mathrm{PF}_{6}$ was added and the resulting precipitate was filtered and washed several times with ethanol followed by diethyl ether.

$\left[\mathrm{Mn}(\mathrm{Fctpy})_{2}\right]\left[\mathrm{PF}_{6}\right]_{2}$ (1): Pinkish crystals, yield: 60\%; m. pt. $>300{ }^{\circ} \mathrm{C}$; Elemental analysis calcd (\%) for $\mathrm{C}_{50} \mathrm{H}_{38} \mathrm{~N}_{6} \mathrm{Fe}_{2} \mathrm{P}_{2} \mathrm{~F}_{12} \mathrm{Mn}$ : $\mathrm{C}$ 50.89, H 3.22, N 7.12; found: C 50.64, H 3.54, N 7.00; ES-MS: $m / z$ :
$1034\left[\mathrm{M}-\mathrm{PF}_{6}\right]^{+} ; \operatorname{FTIR}(\mathrm{KBr}): v_{\max / \mathrm{cm}}^{-1}: 1606(\mathrm{C}=\mathrm{N}), 471(\mathrm{Mn}-\mathrm{N}) ;{ }^{1} \mathrm{H}$ NMR (300 MHz, CD $\left.{ }_{3} \mathrm{CN}\right) \delta(\mathrm{ppm}): 8.781$ (s, $\left.4 \mathrm{H}, \mathrm{py}\right), 8.646$ (s, 4H, py), 8.513 (s, 4H, py), 8.029 (s, 4H, py), 7.525 (s, 4H, py), 5.071 (s, 4H, fc), 4.560 (s, 4H, fc), 4.099 (s, 10H, fc).

$\left[\mathrm{Co}(\text { Fctpy })_{2}\right]\left[\mathrm{PF}_{6}\right]_{2}$ (2): Pinkish crystals, yield: 69\%; m. pt. $>300{ }^{\circ} \mathrm{C}$; Elemental analysis calcd (\%) for $\mathrm{C}_{50} \mathrm{H}_{38} \mathrm{~N}_{6} \mathrm{Fe}_{2} \mathrm{P}_{2} \mathrm{~F}_{12} \mathrm{Co}$ : C 50.71, H 3.21, N 7.10; found: C 50.34, H 3.32, N 6.80; ES-MS: $m / z$ : $1038\left[\mathrm{M}-\mathrm{PF}_{6}\right]^{+}$; FTIR $(\mathrm{KBr}): v_{\max / \mathrm{cm}}^{-1}: 1620(\mathrm{C}=\mathrm{N}), 496(\mathrm{Co}-\mathrm{N}) ;{ }^{1} \mathrm{H}$ NMR $\left(300 \mathrm{MHz}, \mathrm{CD}_{3} \mathrm{CN}\right) \delta(\mathrm{ppm}): 8.819-8.688$ (m, 6H, py), 7.4817.376 (m, 8H, py), 7.180 (bs, 6H, py), 5.534 (bs, 6H, fc), 5.074 (bs, 6H, fc), 4.481 (bs, $6 \mathrm{H}, \mathrm{fc}$ ).

[Ni(Fctpy $\left.)_{2}\right]\left[\mathrm{PF}_{6}\right]_{2}$ (3): Pinkish crystals, yield: 72\%; m. pt. $>300{ }^{\circ} \mathrm{C}$; Elemental analysis calcd (\%) for $\mathrm{C}_{50} \mathrm{H}_{38} \mathrm{~N}_{6} \mathrm{Fe}_{2} \mathrm{P}_{2} \mathrm{~F}_{12} \mathrm{Ni}$ : $\mathrm{C}$ 50.73, H 3.21, N 7.10; found: C 50.68, H 3.56, N 7.41; ES-MS: $m / z$ : $1037\left[\mathrm{M}-\mathrm{PF}_{6}\right]^{+} ; \mathrm{FTIR}(\mathrm{KBr}): v_{\max / \mathrm{cm}}^{-1} 1606(\mathrm{C}=\mathrm{N}), 472(\mathrm{Ni}-\mathrm{N}) ;{ }^{1} \mathrm{H}$ NMR (300 MHz, CD $\left.{ }_{3} \mathrm{CN}\right) \delta$ (ppm): 8.639 (bs, $\left.8 \mathrm{H}, \mathrm{py}\right), 8.152-8.002$ (m, 6H, py), 7.121 (bs, 6H, py), 5.093-4.795 (m, 8H, fc), 4.131-3.926 (m, 10H, fc).

$\left[\mathrm{Cu}(\text { Fctpy })_{2}\right]\left[\mathrm{PF}_{6}\right]_{2}$ (4): Pinkish crystals, yield: 70\%; m. pt. $>300{ }^{\circ} \mathrm{C}$; Elemental analysis calcd (\%) for $\mathrm{C}_{50} \mathrm{H}_{38} \mathrm{~N}_{6} \mathrm{Fe}_{2} \mathrm{P}_{2} \mathrm{~F}_{12} \mathrm{Cu}$ : $\mathrm{C}$ 50.52, H 3.20, N 7.07; found: C 50.81, H 3.47, N 7.45; ES-MS: $m / z$ : $1042\left[\mathrm{M}-\mathrm{PF}_{6}\right]^{+} ;$FTIR $(\mathrm{KBr}): v_{\max / \mathrm{cm}}^{-1}: 1611(\mathrm{C}=\mathrm{N}), 483(\mathrm{Cu}-\mathrm{N}) ;{ }^{1} \mathrm{H}$ NMR (300 MHz, CD 3 CN) $\delta$ (ppm): 9.553 (bs, 3H, py), 8.690 (bs, $4 \mathrm{H}$, py), 8.269 (bs, $4 \mathrm{H}, \mathrm{py}$ ), 7.370 (bs, $4 \mathrm{H}, \mathrm{py}$ ), 7.181 (bs, 5H, py), 5.480 (s, 3H, fc), 4.489 (bs, 5H, fc), 4.051 (s, 10H, fc).

$\left[\mathrm{Zn}(\text { Fctpy })_{2}\right]\left[\mathrm{PF}_{6}\right]_{2}$ (5): Pinkish crystals, yield: $68 \%$; m. pt. $>300{ }^{\circ} \mathrm{C}$; Elemental analysis calcd (\%) for $\mathrm{C}_{50} \mathrm{H}_{38} \mathrm{~N}_{6} \mathrm{Fe}_{2} \mathrm{P}_{2} \mathrm{~F}_{12} \mathrm{Zn}$ : $\mathrm{C}$ 50.44, H 3.19, N 7.06; found: C 50.16, H 3.52, N 6.78; ES-MS: $m / z$ : $1044\left[\mathrm{M}-\mathrm{PF}_{6}\right]^{+} ;$FTIR $(\mathrm{KBr}): v_{\max / \mathrm{cm}}^{-1}: 1603(\mathrm{C}=\mathrm{N}), 477(\mathrm{Zn}-\mathrm{N}) ;{ }^{1} \mathrm{H}$ NMR (300 MHz, $\mathrm{CD}_{3} \mathrm{CN}$ ) $\delta$ (ppm): 9.113-9.093 (m, 4H, py), 9.031 (bs, $4 \mathrm{H}, \mathrm{py}), 8.314-8.276$ ( $\mathrm{m}, 4 \mathrm{H}, \mathrm{py}), 7.932$ (bs, 4H, py), 7.5377.506 (m, 4H, py), 5.668 (s, 4H, fc), 4.857 (s, 4H), 4.421 (s, 2H), 4.331 $(\mathrm{s}, 8 \mathrm{H})$.

\subsection{Pharmacological procedures}

\subsubsection{Toxicity to $B A L B / c$ mouse splenocytes}

BALB/C mouse splenocytes were placed into 96-well plates at a cell density of $5 \times 10^{6}$ cells/well in RPMI-1640 medium supplemented with $10 \%$ of FCS (fetal calf serum, purchased from Gibco sera, Carlsbad, USA) and $50 \mu \mathrm{g} \mathrm{mL}^{-1}$ of gentamycin. Each test inhibitor was used in five concentrations $(0.1,1.0,10,50$, and $100 \mu \mathrm{g} \mathrm{mL}^{-1}$ ) in triplicate. To each well, an aliquot of test inhibitor suspended in DMSO was added, in addition to wells only containing either solvent (untreated cells) or gencian violet (drug control). Then, the plate was incubated for $24 \mathrm{~h}$ at $37{ }^{\circ} \mathrm{C}$ and $5 \% \mathrm{CO}_{2}$. After incubation, $1.0 \mu \mathrm{Ci}$ of ${ }^{3} \mathrm{H}$-thymidine was added to each well, and the plate was returned to the incubator. The plate was then transferred to a $\beta$-radiation counter, and the percent of ${ }^{3} \mathrm{H}$-thymidine was determined. Cell viability was measured as the percent of ${ }^{3} \mathrm{H}$ thymidine incorporation for treated-cells in comparison to untreated cells.

\subsubsection{Antiamoebic activity}

The ligand Fctpy and its metal complexes were screened against the HM1:IMSS strain of E. histolytica by using the microplate method [48]. All the experiments were carried out in triplicates at each concentration level and repeated thrice. E. histolytica trophozoites were cultured in TYI-S-33 growth medium in wells of 96-well microtiter plates [49]. DMSO $(40 \mu \mathrm{L})$ was added to all the samples $(1 \mathrm{mg}$ ) followed by enough culture medium to obtain concentration of $1 \mathrm{mg} / \mathrm{mL}$. The maximum concentration of DMSO in the test did not exceed $0.1 \%$, and at this level no inhibition of amoebal growth had occurred. Compounds were further diluted with medium to a concentration of $0.1 \mathrm{mg} /$ 
mL. Twofold serial dilutions were made in the wells of 96-well microtiter plate. Each test included metronidazole (MNZ) as the standard amoebicidal drug, control (culture medium plus parasite) and a blank (culture medium only). The cell suspension was then diluted to 105 organism/mL by adding fresh medium and $170 \mu \mathrm{L}$ of this suspension was added to the test and control well in the plate. Plate was sealed and gassed for $10 \mathrm{~min}$ with nitrogen before incubation at $37{ }^{\circ} \mathrm{C}$ for $72 \mathrm{~h}$. After incubation, the growth of amoebae in the plate was checked with a low power microscope and the optical density of the solution in each well was determined at $490 \mathrm{~nm}$ with a microplate reader. The \% inhibition of amoebal growth was calculated from the optical densities of the control and test wells and plotted against the logarithm of the dose of the drug tested. Linear regression analysis was used to determine the best-fitted straight line from which the $\mathrm{IC}_{50}$ value was found.

\subsubsection{Antimalarial activity}

W2 strain $P$. falciparum was maintained in continuous culture of human erythrocytes (blood group $\mathrm{O}^{+}$) using RPMI 1640 medium supplemented with $10 \%$ human plasma. Parasites grown at $1-2 \%$ parasitemia and $2.5 \%$ hematocrit were incubated with the testinhibitors at five different concentrations, diluted with $4 \%$ DMSO in culture medium (RPMI 1640) without hypoxanthine. Cultures containing parasites were harvested using a cell harvester to evaluate the $\left[{ }^{3} \mathrm{H}\right]$-hypoxanthine incorporation in a $\beta$-radiation counter. Inhibition of parasite growth was evaluated by comparison with $\left[{ }^{3} \mathrm{H}\right]$-hypoxanthine uptake in drug treated versus untreated wells after $24 \mathrm{~h}$ of incubation with the tested compounds. $\mathrm{IC}_{50}$ values were calculated in triplicate concentration, comparing with the mefloquine (MQN) as standard drug.

\subsubsection{Antiproliferative activity for T. cruzi epimastigotes}

Y strain epimastigotes were counted in a hemocytometer and then dispensed into a 96-well plate at a cell density of $10^{6}$ cells/ well. Test inhibitors, dissolved in DMSO, were diluted to five different concentrations $(0.1,1.0,10,50$, and $100 \mu \mathrm{g} / \mathrm{mL})$ and added to the respective wells in triplicate. The plate was incubated for 11 days at $26{ }^{\circ} \mathrm{C}$, and aliquots of each well were collected and the number of viable parasites were counted in a Neubauer chamber, and compared to untreated parasite culture. $\mathrm{IC}_{50}$ was calculated using non-linear regression on Prism 4.0 GraphPad software. This experiment was done in duplicate, and benznidazole (LAFEPE, Pernambuco, Brazil) was used as the reference inhibitor.

\subsubsection{Inhibition of haemin aggregation}

For this assay, $50 \mu \mathrm{L}$ of a fresh $0.5 \mathrm{mg} / \mathrm{mL}$ solution of haemin (hemin) previously dissolved in $0.2 \mathrm{M} \mathrm{NaOH}$ was mixed with a $75 \mu \mathrm{L}$ of $3 \mathrm{M}$ sodium acetate, $25 \mu \mathrm{L}$ of $17.4 \mathrm{M}$ acetic acid and $50 \mu \mathrm{L}$ of the tested-inhibitor (metal complexes). All complexes were tested in five different concentrations, besides the inhibitor-free sample (negative control). After $24 \mathrm{~h}$ of incubation at $37{ }^{\circ} \mathrm{C}$, the resulting solution was spun down for $15 \mathrm{~min}$ at $3500 \mathrm{rpm}$, the supernatant was discarded off and the pellet washed with $200 \mu \mathrm{L}$ of DMSO. This latter step was repeated once and, after a final wash with water, the pellet was dissolved in $150 \mu \mathrm{L} 0.1 \mathrm{M} \mathrm{NaOH}$. Chloroquine was included in each series of experiments as positive control. The absorption at $405 \mathrm{~nm}$ was read using a spectrophotometer. Results are expressed as percentage of inhibition of haemin formation as compared to the relevant negative control result. Experiments were carried out at least twice using data in triplicate and, when achievable, $\mathrm{IC}_{50}$ s were determined.

\section{Acknowledgements}

This work was supported by University Grants Commission (grant \# 41-275/2012(SR), New Delhi, India), FAPESB (PRONEX grant to Milena Soares, Brazil) and CAPES (grant 23038.003155/ 2011-37 to Valeria Pereira).

\section{Appendix A. Supplementary data}

Supplementary data related to this article can be found at http:// dx.doi.org/10.1016/j.ejmech.2014.01.051.

\section{References}

[1] T. Rodrigues, R. Moreira, F. Lopes, Future Med. Chem. 3 (2011) 1-3.

[2] WHO, World Malaria Report, 2011. Geneva, Switzerland.

[3] T. Zhang, S. Stanley, Vaccine 18 (2000) 868-874.

[4] D. Gaucher, K. Chadee, Vaccine 20 (2002) 3244-3253.

[5] K. Watanabe, H. Gatanaga, A. Escueta-de Cadiz, J. Tanuma, T. Nozaki, S. Oka, PLoS Negl. Trop. Dis. 5 (2011) 1318.

[6] K.S. Wu, H.C. Tsai, S.S. Lee, Y.C. Liu, S.R. Wann, Y.H. Wang, M.H. Mai, J.K. Chen, C.L. Sy, K.M. Chen, Y.J. Chen, Y.S. Chen, J. Microbiol. Immunol. Infect. 41 (2008) 456-461.

[7] V. Ali, T. Nozaki, Clin. Microbiol. Rev. 20 (2007) 164-187.

[8] S.L. Stanley Jr., Lancet 361 (2003) 1025-1034.

[9] WHO, Chagas Disease (American Trypanosomiasis) Fact Sheet 340, August 2012.

[10] C.F. Da Silva, G. Batista Dda, G.M. Oliveira, E.M. de Souza, E.R. Hammer, P.B. da Silva, A. Daliry, J.S. Araujo, C. Britto, A.C. Rodrigues, PLoS One 7 (2012) 30356.

[11] G.F. Swiegers, T.J. Malefetse, Chem. Rev. 100 (2000) 3483-3537.

[12] A. Winter, M. Gottschaldt, G.R. Newkome, U.S. Schubert, Curr. Top. Med. Chem. 12 (2012) 158-175.

[13] H. Kon, K. Tsuge, T. Imamura, Y. Sasaki, S. Ishizaka, N. Kitamura, Inorg. Chem. 45 (2006) 6875-6883.

[14] M. Gagliardo, J. Perelaer, F. Hartl, G.P.M. van Klink, G. van Koten, Eur. J. Inorg. Chem. (2007) 2111-2120.

[15] A.G. Hyslop, M. Orphanide, U. Javed, E.G. Megehee, Inorg. Chim. Acta 355 (2003) 272-279.

[16] E.C. Constable, Chem. Soc. Rev. 36 (2007) 246-253.

[17] U.S. Schubert, H. Hofmeier, G.R. Newkome, Modern Terpyridine Chemistry, Wiley-VCH, Weinheim, 2006.

[18] S. Bonse, J.M. Richards, S.A. Ross, G. Lowe, R.L. Krauth-Siegel, J. Med. Chem. 43 (2000) 4812-4821.

[19] Z. Long-Xuan, Y.S. Moon, A. Basnet, E.K. Kim, Y. Jahng, J.G. Park, T.C. Jeong, W.J. Cho, S.U. Choi, C.O. Lee, S.Y. Lee, C.S. Lee, E.S. Lee, Bioorg. Med. Chem. Lett. 14 (2004) 1333-1337.

[20] L.X. Zhao, T.S. Kim, S.H. Ahn, T.H. Kim, E.K. Kim, W.J. Cho, H. Choi, C.S. Lee, J.A. Kim, T.C. Jeong, C.J. Chang, E.S. Lee, Bioorg. Med. Chem. Lett. 11 (2001) 2659-2662.

[21] I. Eryazici, C.N. Moorefield, G.R. Newkome, Chem. Rev. 108 (2008) 1834-1895.

[22] G. Lowe, A.S. Droz, T. Vilaivan, G.W. Weaver, L. Tweedale, J.M. Pratt, P. Rock, V. Yardley, S.L. Croft, J. Med. Chem. 42 (1999) 999-1006.

[23] O. Inhoff, J.M. Richards, J.W. Brîet, G. Lowe, R.L. Krauth-Siegel, J. Med. Chem. 26 (2002) 4524-4530.

[24] D. Dive, C. Biot, Chem. Med. Chem. 3 (2008) 383-391.

[25] L. Delhaes, C. Biot, L. Berry, P. Delcourt, L.A. Maciejewski, D. Camus, J.S. Brocard, D. Dive, ChemBioChem 3 (2002) 418-423.

[26] U. Siemeling, J. Vor der Brüggen, U. Vorfeld, B. Neumann, A. Stammler, H.G. Stammler, A. Brockhinke, R. Plessow, P. Zanello, F. Laschi, F. Fabrizi-deBiani, M. Fontani, S. Steenken, M. Stapper, G. Gurzadyan, Chemistry 16 (2003) 2819-2833.

[27] G. Jaouen, S. Top, A. Vessires, G. Leclercq, M.J. McGlinchey, Curr. Med. Chem. 11 (2004) 2505-2517.

[28] M.B.P. Soares, J.F.O. Costa, M.S. de Sa, R. Ribeiro-Dos-Santos, P. Pigeon, G. Jaouen, A.E.G. Santana, M.O.F. Goulart, E. Hillard, Drug. Dev. Res. 71 (2010) $69-75$.

[29] E.C. Constable, A.J. Edwards, R.M. Manez, P.R. Raithby, A.M.W. Cargill Thompson, J. Chem. Soc. Dalton Trans. 5 (1994) 645-649.

[30] N. Bharti, M.R. Maurya, F. Naqvi, A. Azam, Bioorg. Med. Chem. Lett. 10 (2000) $2243-2245$.

[31] N. Bharti, M.R. Maurya, F. Naqvi, A. Bhattacharya, S. Bhattacharya, A. Azam, Eur. J. Med. Chem. 35 (2000) 481-486.

[32] N. Bharti, S. Singh, M.T.G. Garza, D.E. Cruz-Vega, J. Castro-Garza, K. Saleem, F. Naqvi, M.R. Maurya, A. Azam, Bioorg. Med. Chem. Lett. 12 (2002) 869-871.

[33] S. Singh, N. Bharti, F. Naqvi, A. Azam, Bioorg. Med. Chem. Lett. 13 (2003) 689692.

[34] S. Singh, N. Bharti, F. Naqvi, A. Azam, Eur. J. Med. Chem. 39 (2004) 459-465.

[35] J. Wang, G.S. Hanan, Synlett 8 (2005) 1251.

[36] C.H. Krishna, C.M. Mahapatra, A.K. Dash, J. Inorg. Nucl. Chem. 39 (1977) $1253-$ 1258. 
[37] J.R. Lakowicz, Principles of Fluorescence Spectroscopy, third ed., Kluwer Academics/Plenum Publishers, New York, 2006.

[38] K. Hutchison, J.C. Morris, T.A. Nile, J.L. Walsh, D.W. Thompson, J.D. Petersen, J.R. Schoonover, Inorg. Chem. 38 (1999) 2516-2523.

[39] S. Encinas, L. Flamigni, F. Barigelletti, E.C. Constable, C.E. Housecroft, E.R. Schofield, E. Figgemeier, D. Fenske, M. Neuburger, J.G. Vos, M. Zehnder, Chem. Eur. J. 8 (2002) 137-150.

[40] B.J. Hathaway, D.E. Billing, Coord. Chem. Rev. 5 (1970) 143-207.

[41] C.J. Isaac, C. Price, B.R. Horrocks, A. Houlton, M.R.J. Elsegood, W. Clegg, J. Organomet. Chem. 598 (2000) 248-253.

[42] P.V. Bernhardt, P.C. Sharpe, M. Islam, D.B. Lovejoy, D.S. Kalinowski, D.R. Richardson, J. Med. Chem. 52 (2009) 407-415.

[43] M.Z. Hernandes, F.J.D. Pontes, L.C.D. Coelho, D.R.M. Moreira, V.R.A. Pereira, A.C.L. Leite, Curr. Med. Chem. 17 (2010) 3739-3750.
[44] D. Bahl, F. Athar, M.B.P. Soares, M.S. de Sa, D.R.M. Moreira, R.M. Srivastava, A.C.L. Leite, A. Azam, Bioorg. Med. Chem. 18 (2010) 6857-6864.

[45] C.L. Donnici, M.H. Araújo, H.S. Oliveira, D.R.M. Moreira, V.R.A. Pereira, M.A. Souza, M.C.A.B. De Castro, A.C.L. Leite, Bioorg. Med. Chem. 17 (2009) $5038-5043$.

[46] B.G. Tweedy, Phytopathology 55 (1964) 910.

[47] G.M. Sheldrick, SHELXL-97: an Integrated System for Solving and Refining Crystal Structures from Diffraction Data (Revision 5.1), University of Göttingen, Germany, 1997.

[48] C.W. Wright, M.J. O’Neill, J.D. Phillipson, D.C. Warhurst, Antimicrob. Agents Chemother. 32 (1988) 1725-1729.

[49] L.S. Diamond, D.R. Harlow, L.S. Cunnick, Trans. R. Soc. Trop. Med. Hyg. 72 (1978) 431-432. 